\title{
The Limits to Health Care Planning
}

\section{Tom Heller}

The concept of health as a 'thing' to be 'delivered' to other people has led directly to some of the present limitations that are apparent in health care planning in both the 'underdeveloped' and 'overdeveloped' parts of the world. The planning of health care delivery systems has become a highly technical exercise carried out by people eager to establish themselves as a new professional grouping. Their emphasis is on the technical and administrative aspects of health care planning. Insistence on seeing health care planning as a separate, technical speciality retards the concept that the health services can be only one small part of the total environment that actually determines the health levels within any community. Housing, sanitation, nutritional standards and even income distribution are more important than the health services taken by themselves in determining the standards of health of a community. Evidence for this comes from the charting of dramatic improvements in health levels that occurred in Western Europe prior to the introduction of health services and before any effective medical interventions had been developed. There is also evidence from India that a decline in mortality is occurring in response to factors of development other than public health programmes (Krishnan 1975), while in England the region with the poorest provision of health services and the lowest expenditure on preventive and community medicine seems to contain the healthiest people.

It would be unwise, of course, to conclude from this evidence that access to health services is unnecessary, and that measurable levels of health will simply reflect levels of development throughout the world, because we do now have at our disposal a number of medical interventions of proven efficacy. Nevertheless, the major challenge for planners is to develop methods of promoting health with people, taking into account the wider social and political implications of their task, rather than the simple delivery of health care packages to them.

\section{The Geographical Distribution of Services}

By way of illustrating that the present limits to health care planning are other than strictly technical, we examine in further detail one of the problems confronting health care planners. The majority of health care facilities are concentrated in urban centres and used by people living in the close vicinity. The largest hospitals in the major urban centres cream off the greatest proportion of medical resources in terms of medical manpower and financial allocations. In the Third World the majority of people live in rural areas, and they share with the rural inhabitants within 'developed' nations an extreme paucity of resources (Morley 1973). Health care planners perceive this as a problem for health care planning; (Gish 1975) inequalities must be removed by judicious planning and equitable resource allocation. There are $X$ people in the country, and their geographical distribution is such that $Y$ number of health facilities are required in order that $Z$ per cent of the population should be no more than $A$ miles from their nearest facility. Unfortunately we have a total budget for health care resources of only $£ B$, so each facility must not cost more than $B / Y$. Therefore these facilities will have to contain $\mathrm{C}$ beds and be staffed by $D$ trained personnel. Unfortunately we do not happen to have this number of personnel because our educational infrastructure is also underdeveloped, so $\mathrm{D}$ will have to be recruited from pupils who have completed their Nth grade at school etc.

Although very crudely expressed, this scenario is probably not unrecognisable to health care planners the world over. The reason why such an approach is doomed to failure is not because of lack of statistical or analytical skills at the command of the planners. Rather it is because of fundamental limitations to planning health services in this way.

\section{Political Limits to the Planning Process}

The spatial distribution of health care resources reflects the social and political structure of the country. Those with social and political power use it to command more resources of all sorts, including medical resources. The bulk of medical resources therefore comes to be provided in areas where there is a high concentration of people possessing political and economic power. The 'XYZ' approach to planning attempts a progressive redistribution of resources that will be resisted by those with access to most resources. The majority of the medical profession will, similarly, resist the redistributive efforts of the health care planners. This can be seen either in class terms, as doctors protect their class interests, or in more 
personal terms as they resist working in remote rural areas far from the attractions of urban life, familiar culture and private practice. In fact, however, resistance to redistributive plans does not overtly take either form. Rather the profession relies on a defence of 'centres of excellence', 'the maintenance of standards' and speaks out against 'the erosion of professional autonomy'.

Countries relying on the market distribution of resources develop a situation where those without market power receive no medical help. This has been the case in the USA where the health crisis of the poor appears to be exactly similar to the fate of those without market power in many LDCs. On the other hand, in the centrally planned economies health care planning tends to reduce the power of the medical profession, and all reports suggest that this can lead to a more equitable geographical distribution of facilities.

The distribution of medical facilities in those countries lying between the two ends of the spectrum may reflect a political struggle between 'market' and 'central plan' ideologies. In Tanzania, attempts at redistributing health care resources are resisted by powerful elements in the urban elite and from within the established medical profession. (Segall 1972) The same kind of struggle can be witnessed at the present time in the UK, with the present government attempting to introduce measures designed to produce a more equitable distribution of health care, and meeting the opposition of the political right wing supported by strike action from senior members of the medical profession.

A sudden shift of a country along the political spectrum may lead health care systems to change rapidly. This has been seen recently in Australia, (Rhodes 1976) and much more dramatically in Chile. Under the Allende administration there were attempts to deploy medical resources towards preventive and rural services. These were resisted by the majority of the medical profession who went on strike and largely refused to cooperate. After the overthrow of Allende the rural health centres were dismantled, preventive measures ceased and the doctors who had supported the redistributive medical policies were regarded as political opponents of the new regime (Waitzkin 1974).

The conflict that confronts plans for redistributing entire health care systems is also evident when small-scale projects are planned. There have recently been many attempts in rural areas to redistribute resources and move away from total reliance on the high technology skills of the medi- cal profession. Although these projects have been envisaged as a response to the lack of trained personnel, frequently they meet opposition from the established medical profession or their representatives.

In South Korea for example, the monopoly position of doctors is protected by laws specifically forbidding nurses from carrying out any form of treatment (Sibley 1971). In Venezuela, "the proposal (for simplified medicine) was not well received by some of the Colegios de Medicos, it was considered preferable to experiment with it in a remote region, free from prejudice and criticism where it was inconceivable that doctors could ever practice." (Gonzalez 1975).

\section{Planning People}

If it is unrealistic to imagine that the distribution of health services can be planned to follow patterns that diverge widely from the prevailing sociopolitical system, it would also be wrong to imagine that health service personnel will not act in similar ways to their peers. In situations where individuals are subject to central government control, health service personnel will accept directives to work in remote rural areas. Where the society is unused to such directives, health service workers will be subject to the same forces that determine motives within the remainder of society. Similarly if there is a consensus that people should follow decisions derived through a decision-making apparatus within the community itself, then this is a possible method of achieving control over the conduct of health service workers. Health service plans that rely on health service workers being more altruistic, or being subject to controls that differ from those operating in other sectors, will find this constraint acts only as a further limit to planning.

In Iran all medical graduates are drafted for a period of service in the health corps in an attempt to provide a medical service to the rural areas. However, difficulties are encountered because "since physicians dislike living and working in rural areas some physicians do not spend their full quota of time at the station ... (and) many mobile visits are never made, or postponed". (Ronaghy 1973). In India the low level of commitment of rural health centre personnel appears to stem from distaste "for the entire way of life, and not simply for the very poor facilities available there. However as they are required to work for the rural population, they take advantage of the village power structure and confine themselves as far as possible, to satisfy the privileged gentry of the village" (Banerji 1973).

Health care personnel from the rural areas tend 
to follow the other educated members of society in a drift towards the large cities. Auxiliaries use their rural training to obtain positions in towns, and doctors leave the country altogether when it is to their advantage. One rural state in Venezuela lost 46 per cent of its trained health care auxiliaries over nine years (Gonzalez 1975). The emigration pattern of qualified doctors towards the fields they consider to be greener is now well documented. Even in those countries where tough controls are imposed by government to restrict the 'brain drain' these measures prove ineffective in the absence of any general observance of government directives. In Sri Lanka, where, theoretically, rigid emigration control is enforced, the number of doctors leaving the country is equivalent to half the number of new medical graduates (Senewiratne 1975). Britain now relies on the graduates of Third World medical colleges for 60 per cent of her junior medical staff, while the USA receives graduates from Latin America alone whom it would take over $\$ 200 \mathrm{mn}$ to train annually. At the same time it distributes $\$ 20 \mathrm{mn}$ in aid to the same countries (Olak 1973).

\section{Concepts of Health and Health Services}

Utilization of health services will be low if the prospective users do not perceive them as appropriate to their needs. It has frequently been shown that the use of health care facilities, and especially participation in active preventive efforts, is low in those areas of maximum need. In the UK there is evidence that those sectors of the community suffering the highest incidence of cervical cancer make the least use of the freely available screening clinics, that the sector of society with the highest birth rate has the poorest attendance record at family planning clinics and that the socio-economic group suffering the highest mortality and morbidity rates use the national health services less frequently than those of higher status (Townsend 1974). This pattern repeats itself throughout the developing world. In India 74-84 per cent of the inhabitants of villages with long-established, free health centres chose to consult traditional practitioners during their most recent illness, and few requested the assistance of trained personnel during the delivery of their children (Reinke 1973). Similar problems of low utilization have been reported from many other LDCs.

One reason for the low utilization of services seems to be that the services themselves are of very poor quality, inadequately supported with supplies and equipment, and staffed by disaffected personnel. The services offered to those from low social groups are of much lower standard than those offered to members of social groups shared by the providers of the service. Moreover, where the local concept of illness is at variance with that implicit in the 'delivered' health service, the indigenous population will not consider it appropriate to attend for treatment. 'Delivery' may in the future be seen as a brief interlude during which insufficient regard was paid to the people who were ill and when there was an overemphasis on organ specific pathology etc.

\section{Lessons from the Chinese Model}

The new structure of the Chinese health service has been described in detail, and there are glowing reports of its success in improving the health levels of the Chinese people (Sidel 1975). Although firm, objective evidence is so far lacking, it does appear that there has been an enormous improvement in health levels since 1949. Several features can be taken from the descriptions of the new service to illustrate some of the general points made in the earlier sections of this paper.

(i) Changes in the health service were seen as only one part of a more general restructuring of society. As such they are in line with the other changes and could not have succeeded without similar commitments to change being made in virtually every aspect of life.

(ii) Health service personnel were not expected to perform differently, or subject themselves to controls that were in any way different from workers in other spheres.

(iii) The new system was not imposed on the community that it was intended to serve. The controls over the health service form an integral part of a comprehensive community-based decisionmaking apparatus. This has particular relevance to considerations of public health, where the technical and practical components involved in establishing effective preventive measures can be learnt by the community, using established decisionmaking and information channels, and where community responsibility is a feature of the local authority system.

(iv) The new system has been built up from a core of traditional concepts and methods of dealing with disease. Modern interventions with proven effectiveness are incorporated into a system that is well established and widely accepted.

The problem remains as to the relevance of the Chinese experience to health care planners in the rest of the world. Where there have been attempts to introduce elements of a Chinese-type medical system without other accompanying changes, this has met with predictable failure (Ronaghy 1974). 
There are occasional reports that the Chinese system itself is not entirely free from troubles very similar to those affecting health services in other parts of the world (Hsu 1974). Certainly, to advocate that health care plans of the future should involve serious consideration of the underlying principles involved in the establishment of the Chinese model is not to suggest that this should be copied in its entirety, or that health care planners can do nothing except plan, or wait for, a transported cultural revolution.

\section{References}

Banerji, D., 1973, Health Behaviour of Rural Populations, Economic and Political Weekly, Bombay, December.

Gish, O., 1975, Planning the Health Sector: The Tanzanian Case, Croom Helm, London.

Gonzalez, C. L., 1975, Simplified Medicine in the Venezuelan Health Services, in Health by the People, ed. Newell, WHO, Geneva.

Hsu, R. C., 1974, The Barefoot Doctors of the Peoples' Republic of China-Some Problems, New England Journal of Medicine, vol. 291, July.

Krishnan, P., 1975, Mortality Decline in India: Development versus Public Health Programme Hypothesis, Social Science and Medicine, vol. 9. Morley, D., 1973, Paediatric Priorities in the Developing World, Butterworth, London.

Olak, O., 1973, The Migration of Medical Per- sonnel from Latin America to the USA, Paper presented to the Pan American Conference on Health Manpower Planning, Ottowa, September, mimeo.

Rhodes, P., 1976, Health Care under the Fraser Government, British Medical Journal, vol. 1, January.

Ronaghy, H. A., 1973, The Auxiliary Health Worker in Iran, Lancet, vol. II.

Ronaghy, H. A., 1974, Is the Chinese Barefoot Doctor Exportable to Rural Iran?, Lancet, vol. I, June.

Reinke, W. A., 1973, Functional Analysis of Health Needs and Services, Johns Hopkins, Baltimore, mimeo.

Segall, M., 1972, The Politics of Health in Tanzania, in J. F. Rweyemamu et al (eds.) Towards Socialist Planning, Tanzania Publishing House, Dar es Salaam.

Senewiratne, B., 1975, Emigration of Doctors, British Medical Journal, vol. I.

Sibley, J. R., 1971, The Koje-Do Project, Contact, Christian Medical Commission, Geneva.

Sidel, V., 1975, The Health Care Delivery System of the Peoples' Republic of China, in Newell, (ed.) Health by the People, WHO, Geneva.

Townsend, P., 1974, Inequality and the Health Service, Lancet, vol. I, June.

Waitzkin, 1974, Medicine, Socialism and Totalitarianism: Lessons from Chile, New England Journal of Medicine, July. 